\title{
Economic Integration, Asymmetries and the Desirability of a Monetary Union
}

\author{
Martine Carré \\ Euréqua - Université de Paris I and Crest \\ Sandrine Levasseur \\ Care-Université de Rouen \\ Franck Portier* \\ Gremaq, Leerna \& Idei, \\ Université des Sciences Sociales de Toulouse
}

\begin{abstract}
Symmetry of shocks across countries is often considered as a necessary condition for a monetary union. We show that the measure of shocks symmetry does not reveal a deep parameter, and depends on economic integration. The more integrated economies are, the more asymmetric are GDPs for a given set of sectoral shocks.
\end{abstract}

- JEL Classifications: E3, F15

- Key Words: Monetary Union - Asymmetry

* Correspondence Address: IDEI, Université des Sciences Sociales, Place Anatole France, F-31042 Toulouse, France, (E-mail) fportier@cict.fr.; Martine Carré, Euréqua, Université de Paris I, 90 rue de Tolbiac, 75634 Paris Cedex 13, France. (E-mail) carrem@univ-paris1.fr; Sandrine Lavasseur, Université de Rouen, 1 rue Thomas Beckett, 76821 Mont Saint Aignan Cedex, France. (E-mail) Sandrine.Levasseur@univ-rouen.fr, Corresponding author

We thank Antoine d'Autume, J.M. Tallon and A. Bossard for helpful comments and suggestions. Errors and omissions remain our responsibility.

(C)2000 - Center for International Economics, Sejong Institution. All rights reserved. 


\section{Introduction}

The European Monetary Union is generally considered as the last step towards European economic integration. On the one hand, in an integrated trade area, it is optimal to create a monetary union in the sense of McKinnon [1963], since flexible rates could give rise to excessive volatility and useless distortions in international relative prices. On the other hand, if there is little labor mobility, wage rates flexibility, and fiscal policies coordination (as it is the case in Europe), an exogenous asymmetric shock would be better accommodated by exchange rates policies. Therefore, as discussed initially by Mundel [1961], the predominance of symmetric shocks (versus asymmetric ones) is a condition for Europe to gain from a single currency.

We propose here a simple model that shows that the measure of asymmetry generally used in the literature does not reveal a structural parameter, and depends on economic integration: the more two countries will be engaged in trade, the more they will be specialized (as shown in Krugman [1991]) and the more asymmetric will be the effect of sectoral shocks.

Starting with Cohen and Wyplosz [1989], a large amount of studies have tried to measure the degree of asymmetry in shocks and responses within Europe, and to compare it with the U.S. situation (see for example Eichengreen [1990], Weber [1990], Bayoumi and Eichengreen [1993], Bini-Smaghi and Vori [1993] and Krugman [1993]. More recently, some papers have extended the analysis to regional and sectoral shocks, in the lines of Stockman [1988] (Bayoumi and Prasad [1997], Bini-Smaghi and Vori [1993] and Helg, Manasse, Monacelli, and Rovelli [1995]). From these studies, one cannot draw some direct conclusion that shocks are far more asymmetric in Europe that they are in the U.S. In the literature, it is nevertheless always implicit (or explicit in in Helg, Manasse, Monacelli, and Rovelli [1995]) that sectoral shocks are rather symmetric (because they hit one sector in all countries), and that regional shocks are, by nature, asymmetric.

According to us, when interpreting shocks as symmetric or asymmetric, and in evaluating the desirability of the EMU in the light of the degree of asymmetry of shocks, one should bear in mind two facts.

First, as stated before, the EMU will be the final touch to the economic 
integration process started in the late 1950s with progressive trade liberalization within the European Union (E.U.). Sapir [1992] distinguishes three major phases in trade liberalization: (i) starting in 1958, progressive elimination of customs duties and quantitative restrictions, completed by a common external tariff in 1968, (ii) successive enlargements from six to twelve between 1973 and 1986, (iii) completion of the internal market for goods, services, capital and labor in 1992. Such an economic integration is theoretically supposed to increase regions (countries) specialization, because there exists some increasing returns (Krugman [1991]), or because countries have some comparative advantage. The question of whether such a specialization is between industries, within industries or both is an empirical matter. Helg, Manasse, Monacelli, and Rovelli [1995] showed that the more specialized countries in Europe were those of Northern-Europe (Luxembourg, Germany, Netherlands, U.K., Belgium and France), and that the less specialized were Spain, Portugal and Greece. It seems that countries that started earlier economic integration through trade liberalization are the more specialized. Bini-Smaghi and Vori [1993] also show that on average, the differences between regional production structure were much larger within the U.S. than within the E.U., and that E.U. national economies were still much more alike than U.S. regions. Such a result is also found in Krugman [1991]. Since trade liberalization is much more recent in the E.U. than in the U.S., this confirms the trend towards specialization created by trade liberalization.

The second fact concerns the importance of sectoral shocks in the variability of regions activity within an economic area (the U.S. or Europe). BiniSmaghi and Vori [1993] show that, considering the founding members of the E.U., from 1976 to 1990 , over 60\% of the variance of manufacturing production explained by sector-specific and state-specific factors is accounted for by sector-specific factors, $15 \%$ by state-specific factors, and the remainder by the interaction of the two. Furthermore, the weight of the state-specific factors falls to $10 \%$ for the period 1981-1990. Using data on the whole economy, and not just manufacturing, Bayoumi and Prasad [1997] find that the relative importance of aggregate, industry-specific and country- or region-specific shocks in explaining output growth fluctuations is roughly similar in Europe and in the U.S. In both case, industry-specific shocks con- 
tribute about one third of the explained variance, with aggregate shocks contributing slightly more and country/region shocks slightly less. Using industrial data, Helg, Manasse, Monacelli, and Rovelli [1995] confirm that more variance of output innovations is firstly explained at the country, but that industry-specific shocks matter to account for output variability.

From this, one can conclude that (i) industry specific shocks are an important source of impulsion in the economy, (ii) trade liberalization creates and will create specialization in Europe. Therefore, for a given distribution of sectoral shocks, the higher trade liberalization is, the higher specialization and asymmetry between countries. Furthermore, economic integration, that is a necessary condition for the EMU, can increase asymmetry and therefore violates another necessary condition for the EMU.

The remainder of the paper is devoted to the analysis of a two-sector, twocountry general equilibrium model that accounts for increasing trade and specialization. Section II presents the model, section III the results and section IV concludes.

\section{The Model}

We use a specific factor model, in the lines of Samuelson [1971]. We consider two economies, $a$ and $b$, whose GDPs are composed of two imperfectly substitutable goods, 1 and 2. Labor is immobile across countries, but perfectly mobile across sectors and is the only production factor. Production functions exhibit decreasing returns to scale. One can think of the technology as using two hidden factors, capital and land, the former being internationally mobile while the latter is not. As far as Gross Domestic Products are concerned, our results are robust to the introduction of those factors. ${ }^{1}$

Each country has a Ricardian advantage in one of the two traded goods and levies taxes on imports. The lower tariff are, the more specialized each economy will be. The two countries are assumed to be as similar as possible.

1. Gross National Products movements will be quite different in a model with internationally mobile factors, given that agents will insure themselves against domestic risk by diversifying their assets. In such models, GNPs are not. 


\section{A. Production}

In each country, there is a fixed amount of labor normalized to one. The production function for sector $i(i=1,2)$ in country $c(c=a, b)$ is given by

$$
Y_{i}^{c}=\left(L_{i}^{c}\right)^{p} X_{i}^{c}
$$

where $L_{i}^{c}$ denotes the labor force employed in sector $i$ of country $c, \rho \in[0$, 1] and $X_{i}^{c}$ is a productivity parameter. We introduce a productivity differential between countries:

$$
\begin{aligned}
& X_{1}^{a}=\left(1+h_{1}\right) X_{1}^{b} \\
& X_{2}^{b}=\left(1+h_{2}\right) X_{2}^{a}
\end{aligned}
$$

with $h_{1}>0$ and $h_{2}>0$. The country $a$ (resp. $b$ ) has a advantage in producing $\operatorname{good} 1$ (resp. 2).

\section{B. Household}

In each country, there is a representative consumer, with identical preferences across countries. Each household offers in its country an inelastic labor supply of one unit. The production technologies are supposed to be owned locally and tariff income entirely transferred to consumers in a lump sum way.

Household of country a maximizes an utility function $U\left(C_{1}^{a}, C_{2}^{a}\right)$ subject to the budget constraint

$$
p_{1}^{a} C_{1}^{a a}+(1+d) p_{1}^{b} C_{1}^{a b}+p_{2}^{a} C_{2}^{a a}+(1+d) p_{2}^{b} C_{2}^{a b} \leq p_{1}^{b} Y_{1}^{a}+p_{2}^{a} Y_{2}^{a}+T^{a}
$$

where $C_{i}^{a c}$ is the consumption of good $i$, bought in country $c, d$ is the tariff, $T^{a}$ is a lump sum transfer, $p_{i}^{c}$ is the price of good $i$ produced in country $c$. At the aggregate level, we have $T^{a}=d\left(p_{1}^{b} C_{1}^{a b}+p_{2}^{b} C_{2}^{a b}\right)$, since the product of the tariff is entirely redistributed. Household's preferences are given by the following CES utility function:

$$
U^{a}\left(C_{1}^{a}, C_{2}^{a}\right)=\left[\alpha\left(C_{1}^{a}\right)^{\gamma}+(1-\alpha)\left(C_{2}^{a}\right)^{\gamma}\right]^{1 / \gamma}
$$

where $\gamma<1, \sigma=1 /(1-\gamma)$ is the elasticity of substitution between $C_{1}^{a}$ and $C_{2}^{a}$. All these equations can be written symmetrically for household $b$. To be of some empirical relevance, we will assume that $\sigma$ is large, i.e. that goods are close substitutes. This choice is motivated by the fact that most of the trade 
between countries joining a Economic and Monetary Union is intra-sectorial, i.e. consists in exchanges of closely substitutable goods.

\section{Equilibrium}

Equilibrium allocation can be computed as a set of prices and quantities such that (i) for these prices, the quantities are the ones that maximize agents' objective given their resource constraints, (ii) markets clear. In the following, we choose the first good in country $a$ as numÇraire, and real GDP will be denoted $G D P^{c}=\left(p_{1}^{c} Y_{1}^{c}+p_{2}^{c} Y_{2}^{c}\right) / p_{1}^{a}$. No closed form solution can be found for the equilibrium, and we proceed by mean of numerical simulations to get the results presented in the next section.

\section{Results}

It is tedious but straightforward to show analytically that as the tariff rate $d$ decreases, country $a$ specializes in good 1 and country $b$ in good 2 . Beyond specialization, we are concerned with asymmetries between countries. We propose a simulation of our model that shows that, for a time invariant set of sectoral shocks, a downward trend in tariff, by increasing specialization and economic integration, lowers the correlation between GDPs and increases the measured share of asymmetric shocks in the variance of GDP's.

In the calibration we considered (results can be shown to be robust to the calibration), goods are close substitutes (the elasticity of substitution is set to $\sigma=10$ ) and countries are symmetric with respect to preferences, advantage, tariff and production functions. The simulation parameters are displayed in table 1 . We assume that output elasticity to labor input is .5 in all sectors and all countries. Furthermore, each country is twice more productive that the other in producing one good, and twice less in producing the other.

Table 1

\section{Parameters Calibration}

\begin{tabular}{|c|c|c|c|c|}
\hline$\alpha$ & $\gamma$ & $h_{1}$ & $h_{2}$ & $\rho$ \\
\hline 0.5 & 0.9 & 0.5 & 0.5 & 0.5 \\
\hline
\end{tabular}


Table 2

Results from Simulations

\begin{tabular}{|c|c|c|c|c|}
\hline $\begin{array}{c}\text { Tariff } \\
(\mathrm{d})\end{array}$ & $\begin{array}{c}\text { GDP } \\
\text { Correlation }\end{array}$ & $\begin{array}{c}\text { Sym. Shocks } \\
\left(\alpha^{+}\right)\end{array}$ & $\begin{array}{c}\text { Asym. Shocks } \\
\left(\alpha^{-}\right)\end{array}$ & $\begin{array}{c}\text { Measure of Asym. } \\
\left(\frac{\sigma^{+}}{\sigma^{-}}\right)\end{array}$ \\
\hline 0.50 & 1.0000 & 1.22 & 0.00 & $\infty$ \\
0.45 & 0.9998 & 1.18 & 0.02 & 60.8 \\
0.40 & 0.9978 & 1.14 & 0.04 & 27.7 \\
0.35 & 0.9959 & 1.11 & 0.07 & 16.9 \\
0.30 & 0.9930 & 1.07 & 0.09 & 11.6 \\
0.25 & 0.9888 & 1.04 & 0.12 & 8.5 \\
0.20 & 0.9833 & 1.01 & 0.15 & 6.6 \\
0.15 & 0.9761 & 0.99 & 0.19 & 5.3 \\
0.10 & 0.9673 & 0.97 & 0.22 & 4.4 \\
0.05 & 0.9572 & 0.95 & 0.25 & 3.8 \\
0.00 & 0.9462 & 0.93 & 0.28 & 3.3 \\
\hline
\end{tabular}

Tariff $d$ is assumed to decrease from $50 \%$ to $0 \%$. For each value $d$ of the tariff, we draw $n \times n$ sectoral shocks $\left(X_{1}^{a}, X_{2}^{b}\right)$, keeping constant advantage. It is assumed that sectoral shocks are the only source of disturbance in the economy. ${ }^{2}$ These sectoral shocks are uniformly distributed over the interval $[0.5,1.5]$, and $n=5$.

For each value of the tariff $d$, we compute the equilibrium for the $n \times n$ $=25$ sectoral shocks couples $\left(X_{1}^{a}, X_{2}^{b}\right)$. In a world with no trade, GDPs will be always equal, their correlation null, and the degree of asymmetry null. This happens when $d=0.5$, since the tariff just offsets the relative advantages of the two countries, such that the two economies are in autarky.

When $d$ decreases, economies open, specialize and become more and more asymmetric, for the same set of 25 sectoral shocks. These results are illustrated in table 2 .

Column 1 displays the value of the tariff. Column 2 displays the correlation coefficient between the two GDPs. Even with a constant distribution of

2. Such an assumption can be relaxed at no cost without changing the qualitative results. 
shocks, this correlation decreases with the tariff, from 1 when $d=0.5$ to nearly 0.95 when $d=0$.

Columns 3 to 5 are related to Cohen and Wyplosz [1989] or Weber [1990] studies, that use an Aoki factorisation of GDPs of two countries to measure the relative importance of symmetric and asymmetric shocks. With our notation, the Aoki factorisation can be written as

$$
\begin{aligned}
& G D P^{a}=\left(G D P^{a}+G D P^{b}\right) / 2+\left(G D P^{a}-G D P^{b}\right) / 2 \\
& G D P^{b}=\left(G D P^{a}+G D P^{b}\right) / 2-\left(G D P^{a}-G D P^{b}\right) / 2
\end{aligned}
$$

$\left(G D P^{a}+G D P^{b}\right)$ can be therefore interpreted as the symmetric component of GDPs, and $\left(G D P^{a}-G D P^{b}\right)$ as the asymmetric component, with respective standard deviations $\sigma^{+}$and $\sigma^{-}$. An increase in the relative size of $\sigma^{-}$is therefore interpreted as an increase in the asymmetry within the area. These standard deviations are presented in columns 3 and 4 , and their ratio in column 5. It is clear form this last column that the area is becoming more and more asymmetric as tariff decrease, since the ratio $\sigma^{+} / \sigma^{-}$is decreasing from infinity when $d=0.5 \%$ (in that case, let us recall that the two GNP are perfectly correlated) to 3 when $d=0 \%$. With such a data set, an econometrician will conclude that shocks are becoming more and more asymmetric. But this ratio is not a structural parameter that characterizes the shocks, since the shocks distribution is always the same. This illustrates the facts that an economic integration process creates endogenously some asymmetry that can become a barrier to monetary union if factors are not mobile.

\section{Conclusion}

We have shown in this paper that an internal contradiction could arise in the economic integration process whose last step should be a monetary union. Because integration means specialization, the same set of sectoral shocks can become more and more destabilizing in terms of asymmetry of GNPs within the area. Such a result shows that there is little hope to get some structural measure of shocks asymmetry as long as economic integration is still in process. Furthermore, the fact that shocks are not much more symmetric in the U.S. than in Europe is not a reason to assess that Europe 
is currency area "almost as optimal" as the U.S., since trade liberalization and integration are done for a long time in the U.S., and still to be achieved in Europe.

\section{References}

Bayoumi, T., and B. Eichengreen [1993], "Shocking Aspects of European Monetary Integration," in Adjustment and Growth in the European Monetary Union, ed. by F. Torres and F. Giavazzi, Chap. 7; pp. 193-229. Cambridge University Press, Cambridge.

Bayoumi, T., and E. Prasad [1997], "Currency Unions, Economic Fluctuations and Adjustment: Some New Empirical Evidence," IMF Staff Papers 44(1); pp. 36-58.

Bini-Smachi, L., and S. Vori [1993], "Rating the E.C. as an Optimal Currency Area," Banca d'Italia Temi de Discussione del Servizio Studi 187.

Cohen, D., and C. Wyplosz [1989], "The European Monetary Union: An Agnostic Evaluation," in Macroeconomic Policies in an Interdependent World, ed. by R. Bryant, D. Currie, J. Frenkel, P. Masson, and R. Portes; pp. 311-37, Washington: International Monetary Fund.

Eichengreen, B. [1990], “One Money for Europe? Lessons from the US Currency Union,” Economic Policy 10; pp. 119-87.

Helg, R., P. Manasse, T. Monacelli, and R. Rovelli [1995], "How Much Asymmetry in Europe? Evidence from Industrial Sectors," European Economic Review 39; pp. 1017-1041.

Krugman, P. [1991], Geography and Trade, MIT Press, Cambridge, Mass.

Krugman, P. [1993], "Lessons of Massachusetts for EMU," in Adjustment and Growth in the European Monetary Union, ed. by F. Torres, and F. Giavazzi, Chap. 8; pp. 241-261, Cambridge University Press, Cambridge.

McKinnon, R. [1963], “Optimum Currency Areas,” American Economic Review 53.

Mundel, R. [1961], "A Theory of Optimum Currency Areas," American Economi Review 51; pp. 657-64.

Samuelson, P. [1971], “Ohlin Was Right” Swedish Journal of Economic 73; pp. 365-384. 
Sapir, A. [1992], “Regional Integration in Europe," Economic Papers 94; pp. $1-21$.

Stockman, A. [1988], "Sectoral and National Aggregate Disturbances," Journal of Monetary Economics 21(2/3); pp. 387-410.

Weber, A. [1990], "EMU and Asymmetries and Adjustment Problems in the EMS.: Some Empirical Evidence,” Discussion Paper 448, CEPR Discussion Paper, London. 